\title{
Combustion Analysis of CI Engine under the Influence of two different Injecting Nozzles
}

\author{
Devangkumar C Patel ${ }^{1}$, Dr. Tushar M Patel ${ }^{2}$, Prof. Dhananjay H Joshi ${ }^{3}$, \\ Prof. Gaurav P Rathod ${ }^{4}$ \\ ${ }^{I}$ (M.E. Scholar, Mechanical Engineering Department, LDRP-ITR, Gandhinagar, India.) \\ ${ }^{2}$ (Professor, Mechanical Engineering Department, LDRP-ITR, Gandhinagar, India.) \\ ${ }_{3}^{3}$ (Assistant Professor, Mechanical Engineering Department, LDRP-ITR, Gandhinagar, India.) \\ ${ }^{4}$ (Lecturer, Mechanical Engineering Department, Government Polytechnic, Godhra, India)
}

\begin{abstract}
The combustion process taking place inside the engine cannot be directly visualized for the analysis purpose but the same can be possible by performing the experiment and listing the data into graphical form and by the curves of graphs we can conclude the main core of the experiment. Generally combustion is divided into three major parts pressure-crank angle study, pressure-volume study \& fuel-line pressure. This paper includes the study of combustion of CI engine when it is experimented by two different types of nozzles. The study gives a brief idea of the amount of pressure and volume attained inside the combustion chamber of CI engine.
\end{abstract}

Keywords: CI engine, Combustion analysis, pressure, volume, fuel line, nozzle

\section{Introduction}

The combustion taking place inside the engine cylinder is heterogeneous form. The $\mathrm{CI}$ engine is having higher thermal efficiency as compared to SI engine. The Thermal efficiency thus depends on the combustion taking place inside the engine cylinder. This paper gives the general idea about the pressure and volume at the respective crank angle. When the combustion is taking place inside the engine cylinder the pressure rises at maximum level near its combustion phenomenon. This rate of rise in pressure is predicted in the pressure-crank angle study by the graphical method [10].

This study also gives the general idea of the change in the volume created by the piston movement inside the cylinder. The exact volume at the respective crank angle along with the rate of pressure is depicted on the pressure-volume study by the graphical method. When the piston moves from TDC to BDC during the suction stroke the volume of combustion chamber increases thereafter when the piston moves from BDC to TDC for the compression stoke the volume is reduced, then after the completion of compression stoke the piston moves from TDC to BDC for the power stoke and during that time the volume increases rapidly and at last at the time of removal of exhaust gases the volume is again reduced to its minimum level by travel of piston from $\mathrm{BDC}$ to TDC $[3,5]$.

The pressure inside the fuel line is also an important aspect of study of combustion process. The Fuel line pressure indicated the amount of pressure inside the fuel line at the time of injection of fuel. This study plays an important role when the focus is made on both the nozzles. For both the nozzles the pressure might be different [1]. The amount of pressure inside the fuel line also relates the fuel consumption of the engine. By the overall study of pressure, volume and fuel line pressure the complete combustion analysis is achieved in a most proper and efficient manner [2]. The Pressure and volume of combustion differs from time to time due to the continuous movement of the piston inside the engine cylinder [4, 8]. The graph also shows the start of combustion and the start of injection of fuel inside the engine. This study helps to get the general working of the engine itself and also the engine with respect to the nozzles.

This Study is further helpful for the design purpose for designing the cylinder of combustion chamber. The inappropriate design may leads to the explosive accidents during the working conditions. The proper material selection phase is also done by this analysis [6].

\section{Experimental Setup}

The setup consists of single cylinder, four stroke, multi-fuel, research engine connected to eddy type dynamometer for loading and DC five gas analyzer connected measures five emission gases, including Hydrocarbons (HC), Carbon Monoxide (CO), Carbon Dioxide (CO2), Oxygen (O2) and Oxides of Nitrogen (NOX) [11]. The operation mode of the engine can be changed from diesel to Petrol of from Petrol to Diesel with some necessary changes [9]. The specification of the research engine is given in table-3. The operation mode of the engine can be changed from diesel to petrol of from petrol to diesel with some necessary changes. In both modes the compression ration can be varied without stopping the engine and without altering the 
combustion chamber geometry by specially designed tilting cylinder block arrangement [7]. The injection point and spark point can be changed for research tests. Setup is provided with necessary instruments for combustion pressure, Diesel line pressure and crank-angle measurements. These signals are interfaced with computer for pressure crank angle diagrams. Instruments are provided to interface airflow, fuel flow, temperatures and load measurements. The set-up has stand-alone panel box consisting of air box, two fuel flow measurements, process indicator and hardware interface. Rota meters are provided for cooling water and calorimeter water flow measurement [12]. A battery, starter and battery charger is provided for engine electric start arrangement. The setup enables study of VCR engine performance for brake power, indicated power, frictional Power, BMEP, IMEP, brake thermal efficiency, indicated thermal efficiency, Mechanical efficiency, volumetric efficiency, specific fuel consumption, A/F ratio. Laboratory view based engine performance analysis software package "Engine soft" is provide for performance of experiment. Figure 2.1 shows the experimental set-up [13].

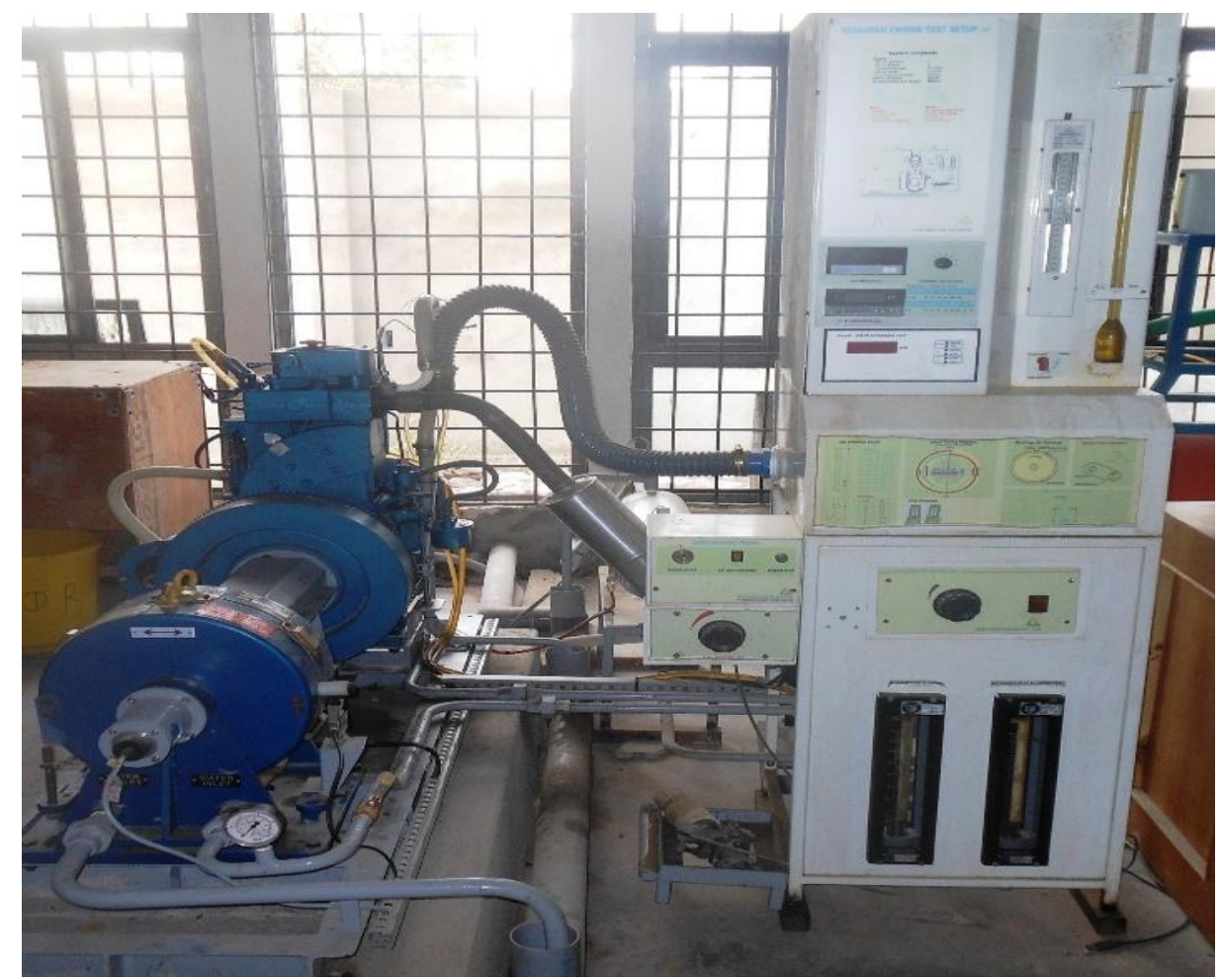

Fig.1: Experimental setup [14]

Table 1: Technical specification of the engine.[15]

\begin{tabular}{|l|l|}
\hline No. of cylinder & Single cylinder \\
\hline No. of stroke & 4 \\
\hline Cylinder dia. & $87.5 \mathrm{~mm}$ \\
\hline Stroke length & $110 \mathrm{~mm}$ \\
\hline C.R. length & $234 \mathrm{~mm}$ \\
\hline Orifice dia. & $20 \mathrm{~mm}$ \\
\hline Dynamometer arm length & $185 \mathrm{~mm}$ \\
\hline Fuel & Diesel \\
\hline Power & $3.5 \mathrm{~kW}$ \\
\hline Speed & $1500 \mathrm{rpm}$ \\
\hline C.R. range & $12: 1$ to $18: 1$ \\
\hline Inj. Point variation & 0 to $25 \mathrm{BTDC}$ \\
\hline
\end{tabular}

\section{Experimental Procedure}

- First of all the water flow for the cooling of engine is turned on and then the engine is cranked with the handle and started.

- During this testing the two-hole nozzle having two holes for the fuel supply is fitted in the engine assembly along with the injector.

- Then the fuel line in the filled with the diesel and allowed to stable.

- The knob for the load is set at load 1 and the pressure is set at the high level by adjusting the pressure adjusting screw on the injector.

- Then the "Enginesoft" software is attached to the engine setup and the start of reading is done. 
- The software takes 60 seconds for taking the reading of any specific reading.

- Then the load and pressure is adjusted as per the table and 21 readings were taken as per table and individual software files are saved.

- Then the engine is stopped and the injector bolts are loosen and the nozzle with two holes is removed from injector and nozzle with single hole is fitted in the injector and the engine is again started.

- The same procedure is followed again for the single-hole nozzle having the single hole for the fuel supply.[16]

IV. Observation

Table 2: Observation Table for Two-hole nozzle

\begin{tabular}{|c|c|c|c|c|c|c|c|c|c|c|}
\hline Ex. No & $\begin{array}{l}\text { Injection } \\
\text { Pressure }\end{array}$ & Load & $\begin{array}{c}\text { Speed } \\
\mathrm{rpm}\end{array}$ & $\begin{array}{c}\mathrm{FC} \\
\mathrm{cc} / \mathrm{min}\end{array}$ & $\begin{array}{c}\text { Air } \\
\mathrm{mmwc}\end{array}$ & $\begin{array}{c}\mathrm{O}_{2} \\
\%\end{array}$ & $\mathrm{CO}_{2} \%$ & $\begin{array}{c}\mathrm{HC} \\
\mathrm{ppm}\end{array}$ & $\begin{array}{c}\mathrm{CO} \\
\%\end{array}$ & $\begin{array}{c}\mathrm{No}_{\mathrm{x}} \\
\mathrm{ppm}\end{array}$ \\
\hline 1 & High & 1 & 1534 & 8 & 59.17 & 19.28 & 0.9 & 10 & 0.07 & 88 \\
\hline 2 & High & 3 & 1529 & 10 & 58.49 & 19.23 & 1.1 & 25 & 0.05 & 184 \\
\hline 3 & High & 5 & 1496 & 12 & 55.81 & 18.66 & 1.3 & 27 & 0.03 & 321 \\
\hline 4 & High & 7 & 1468 & 14 & 53.74 & 18.13 & 1.7 & 34 & 0.03 & 535 \\
\hline 5 & High & 9 & 1468 & 16 & 53.17 & 17.98 & 1.8 & 45 & 0.03 & 769 \\
\hline 6 & High & 11 & 1453 & 18 & 51.89 & 17.52 & 2 & 29 & 0.02 & 837 \\
\hline 7 & High & 13 & 1456 & 21 & 51.22 & 17.33 & 2.1 & 54 & 0.03 & 992 \\
\hline 8 & Medium & 1 & 1544 & 8 & 59.94 & 18.87 & 1 & 25 & 0.06 & 119 \\
\hline 9 & Medium & 3 & 1527 & 10 & 58.5 & 18.91 & 1.1 & 27 & 0.04 & 201 \\
\hline 10 & Medium & 5 & 1517 & 12 & 57.65 & 18.66 & 1.3 & 32 & 0.03 & 339 \\
\hline 11 & Medium & 7 & 1462 & 13 & 53.39 & 18.14 & 1.6 & 41 & 0.03 & 531 \\
\hline 12 & Medium & 9 & 1472 & 16 & 53.16 & 18 & 1.8 & 49 & 0.02 & 795 \\
\hline 13 & Medium & 11 & 1460 & 18 & 52.06 & 17.48 & 2 & 36 & 0.02 & 874 \\
\hline 14 & Medium & 13 & 1461 & 20 & 51.57 & 17.31 & 2.1 & 65 & 0.03 & 1050 \\
\hline 15 & Low & 1 & 1554 & 8 & 60.54 & 19.27 & 1 & 26 & 0.05 & 137 \\
\hline 16 & Low & 3 & 1551 & 10 & 59.92 & 18.87 & 1.1 & 29 & 0.04 & 222 \\
\hline 17 & Low & 5 & 1485 & 11 & 55.79 & 18.56 & 1.4 & 20 & 0.04 & 333 \\
\hline 18 & Low & 7 & 1497 & 14 & 55.99 & 18.44 & 1.5 & 34 & 0.03 & 539 \\
\hline 19 & Low & 9 & 1493 & 16 & 54.94 & 17.98 & 1.8 & 48 & 0.02 & 830 \\
\hline 20 & Low & 11 & 1467 & 18 & 52.67 & 17.57 & 1.9 & 45 & 0.02 & 904 \\
\hline 21 & Low & 13 & 1449 & 21 & 50.85 & 17.27 & 2.1 & 73 & 0.03 & 1066 \\
\hline
\end{tabular}

Table 3: Observation Table for Single-hole nozzle

\begin{tabular}{|c|c|c|c|c|c|c|c|c|c|c|}
\hline Ex. No & $\begin{array}{l}\text { Injection } \\
\text { Pressure }\end{array}$ & Load & $\begin{array}{l}\text { Speed } \\
\text { rpm }\end{array}$ & $\begin{array}{c}\mathrm{FC} \\
\mathrm{cc} / \mathrm{min}\end{array}$ & $\begin{array}{c}\text { Air } \\
\text { mmwc }\end{array}$ & $\begin{array}{l}\mathrm{O}_{2} \\
\%\end{array}$ & $\mathrm{CO}_{2} \%$ & $\begin{array}{l}\mathrm{HC} \\
\mathrm{ppm}\end{array}$ & $\begin{array}{c}\mathrm{CO} \\
\%\end{array}$ & $\begin{array}{l}\mathrm{No}_{\mathrm{x}} \\
\mathrm{ppm}\end{array}$ \\
\hline 1 & High & 1 & 1503 & 12 & 56.88 & 19.47 & 1 & 37 & 0.15 & 12 \\
\hline 2 & High & 3 & 1505 & 10 & 56.97 & 18.92 & 1.3 & 31 & 0.04 & 256 \\
\hline 3 & High & 5 & 1406 & 11 & 51.43 & 18.22 & 1.4 & 33 & 0.03 & 387 \\
\hline 4 & High & 7 & 1442 & 14 & 53.79 & 18.17 & 1.6 & 38 & 0.03 & 460 \\
\hline 5 & High & 9 & 1462 & 16 & 52.37 & 17.66 & 1.8 & 33 & 0.02 & 542 \\
\hline 6 & High & 11 & 1464 & 18 & 51.85 & 17.45 & 1.9 & 45 & 0.02 & 807 \\
\hline 7 & High & 13 & 1454 & 21 & 51.12 & 17.14 & 2.1 & 50 & 0.02 & 951 \\
\hline 8 & Medium & 1 & 1484 & 11 & 55.45 & 19.26 & 1 & 22 & 0.06 & 80 \\
\hline 9 & Medium & 3 & 1486 & 10 & 55.63 & 18.72 & 1.1 & 26 & 0.05 & 123 \\
\hline 10 & Medium & 5 & 1414 & 12 & 49.55 & 18.29 & 1.3 & 32 & 0.04 & 275 \\
\hline 11 & Medium & 7 & 1458 & 14 & 52.24 & 17.98 & 1.6 & 37 & 0.03 & 455 \\
\hline 12 & Medium & 9 & 1455 & 16 & 52.25 & 17.69 & 1.8 & 37 & 0.02 & 612 \\
\hline 13 & Medium & 11 & 1468 & 18 & 52.06 & 17.43 & 2 & 48 & 0.02 & 853 \\
\hline 14 & Medium & 13 & 1458 & 20 & 51.38 & 17.18 & 2.1 & 56 & 0.02 & 983 \\
\hline 15 & Low & 1 & 1504 & 8 & 57.48 & 19.23 & 1 & 28 & 0.08 & 67 \\
\hline 16 & Low & 3 & 1498 & 10 & 56.52 & 18.76 & 1.1 & 28 & 0.05 & 117 \\
\hline 17 & Low & 5 & 1460 & 11 & 53.43 & 18.41 & 1.4 & 35 & 0.04 & 279 \\
\hline 18 & Low & 7 & 1454 & 14 & 52.47 & 17.99 & 1.6 & 41 & 0.03 & 480 \\
\hline 19 & Low & 9 & 1464 & 16 & 52.55 & 17.71 & 1.8 & 41 & 0.02 & 644 \\
\hline 20 & Low & 11 & 1459 & 18 & 51.77 & 17.47 & 1.9 & 51 & 0.02 & 856 \\
\hline 21 & Low & 13 & 1477 & 20 & 52.56 & 17.2 & 2 & 59 & 0.02 & 990 \\
\hline
\end{tabular}




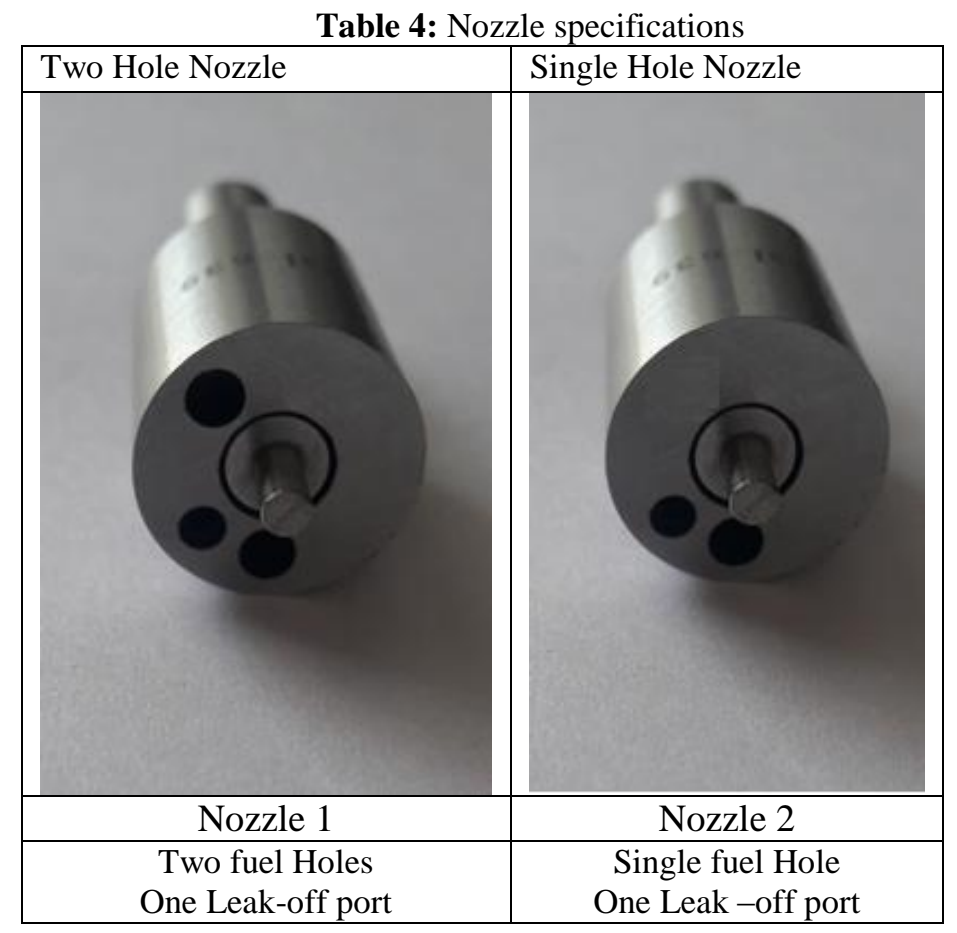

V. Result And Discussion

Discussions of results for Pressure-Crank Angle

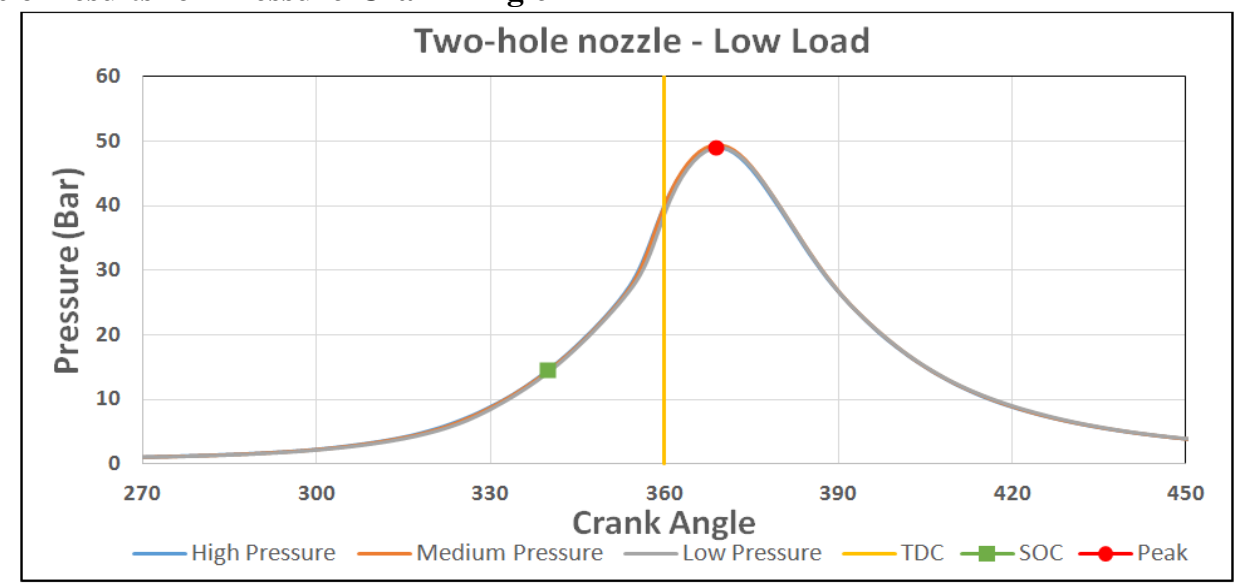

Fig.2: Pressure V/S Crank Angle (P- $\theta$ ) graph for Low Load with two-hole nozzle

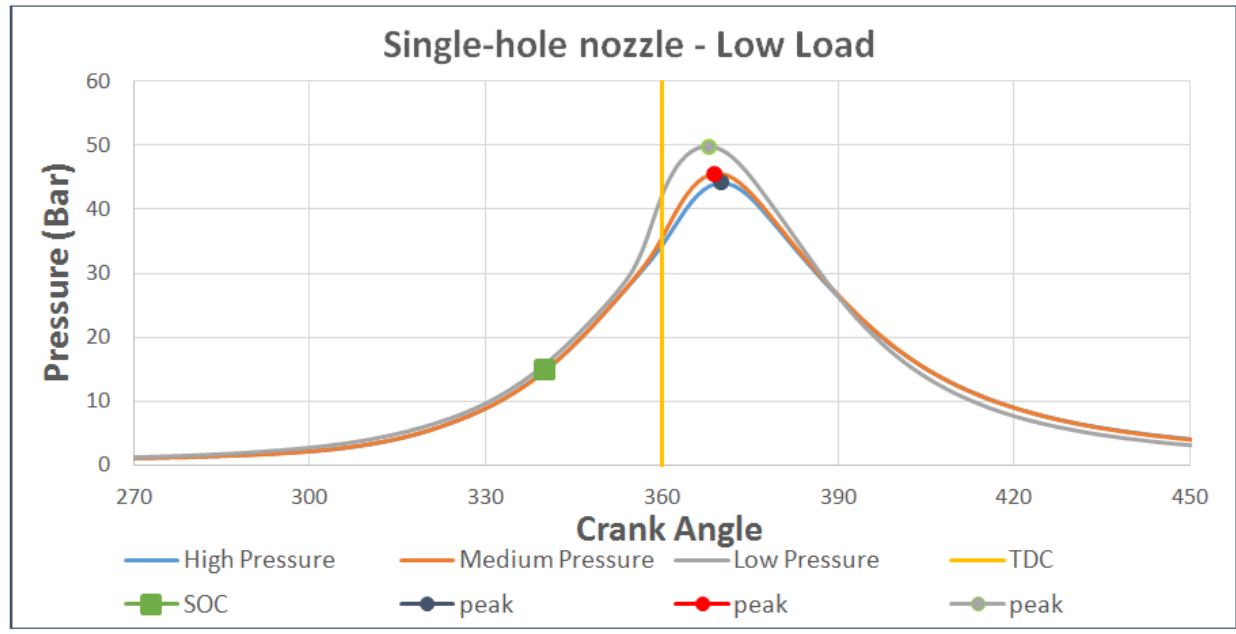

Fig.3: Pressure V/S Crank Angle (P- $\theta$ ) graph for Low Load with single-hole nozzle 
Figure 2 and Figure 3 shows Pressure - Crank Angle (P- $\theta$ ) graph the graph for low load including all the injection pressures. From graph we can conclude that the pressure created by the combustion for all the injection pressure is same for two-hole nozzle whereas different at all the injection pressure for single-hole nozzle. The pressure created by the combustion is at peak level of 50 bar for all injection pressure in two-hole nozzle, while in single-hole nozzle also peak of 50 bar for low injection pressure only.

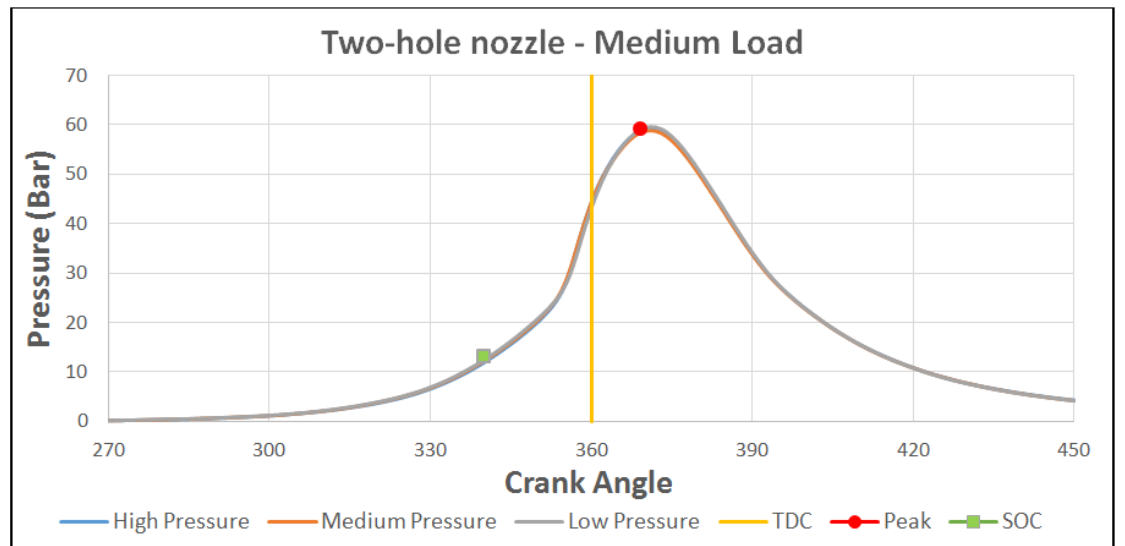

Fig.4: Pressure V/S Crank Angle (P- $-\theta)$ graph for Medium Load with two-hole nozzle

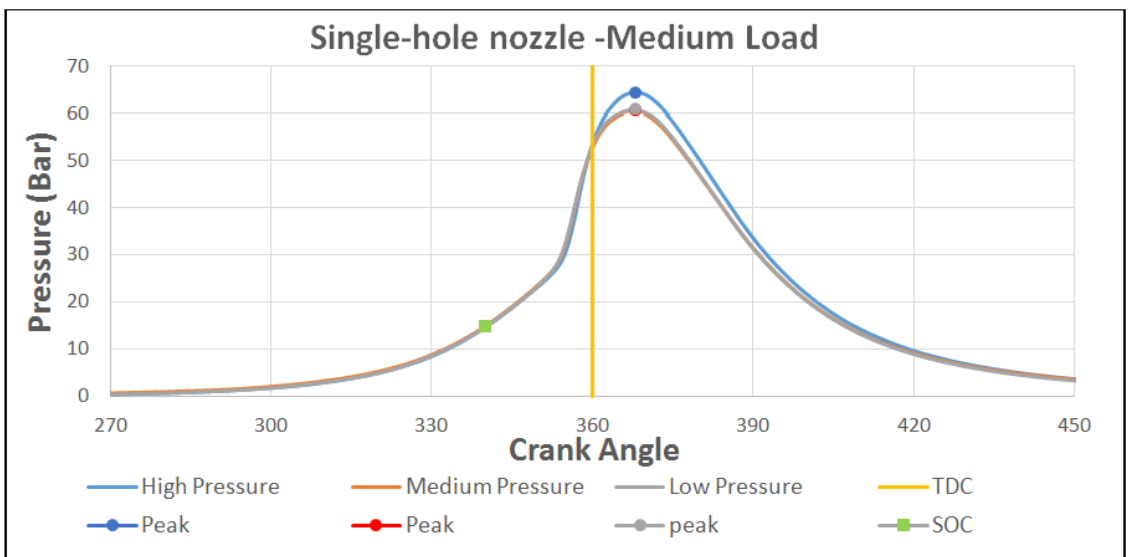

Fig.5: Pressure V/S Crank Angle (P- $\theta$ ) graph for Medium Load with single-hole nozzle

Figure 4 and Figure 5 shows Pressure - Crank Angle (P- $\theta$ ) graph the graph for medium load including all the injection pressures. From graph we can conclude that the pressure created by the combustion for all the injection pressure is same for two-hole nozzle whereas different at all the injection pressure for single-hole nozzle. The pressure created by the combustion is at peak level of 60 bar for all injection pressure in two-hole nozzle, while in single-hole nozzle also peak of 65 bar for high injection pressure only.

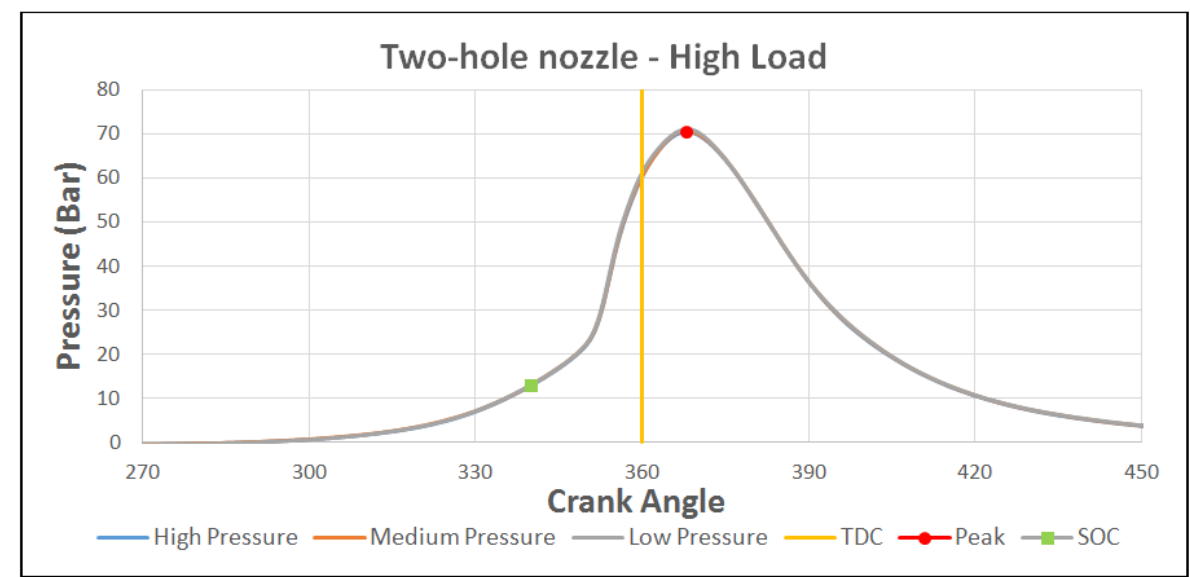

Fig.6: Pressure V/S Crank Angle (P- $\theta)$ graph for High Load with two-hole nozzle 


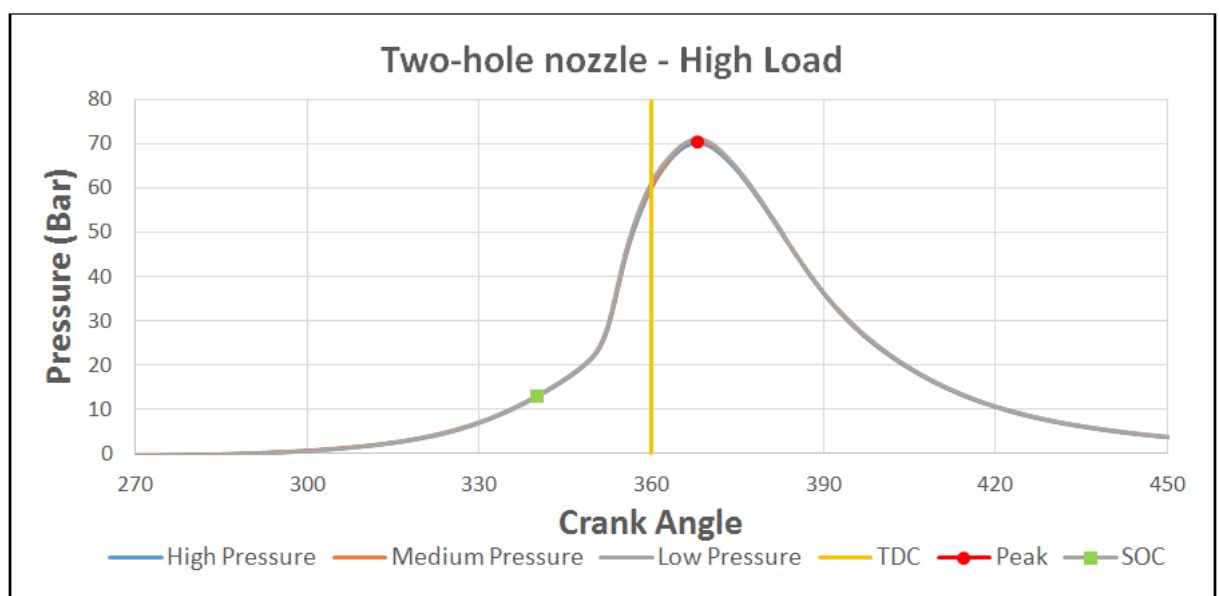

Fig.7: Pressure V/S Crank Angle (P- $\theta$ ) graph for High Load with single-hole nozzle

Figure 6 and Figure 7 shows Pressure - Crank Angle (P- $-\theta)$ graph the graph for high load including all the injection pressures. From graph we can conclude that the pressure created by the combustion for all the injection pressure is same for two-hole nozzle and also same for all the injection pressure for single-hole nozzle.

The pressure created by the combustion is at peak level of 71 bar for all injection pressure in two-hole nozzle, and for single-hole nozzle also peak of 70 bar for all injection pressure.

\section{Discussions of results for Pressure-Volume}

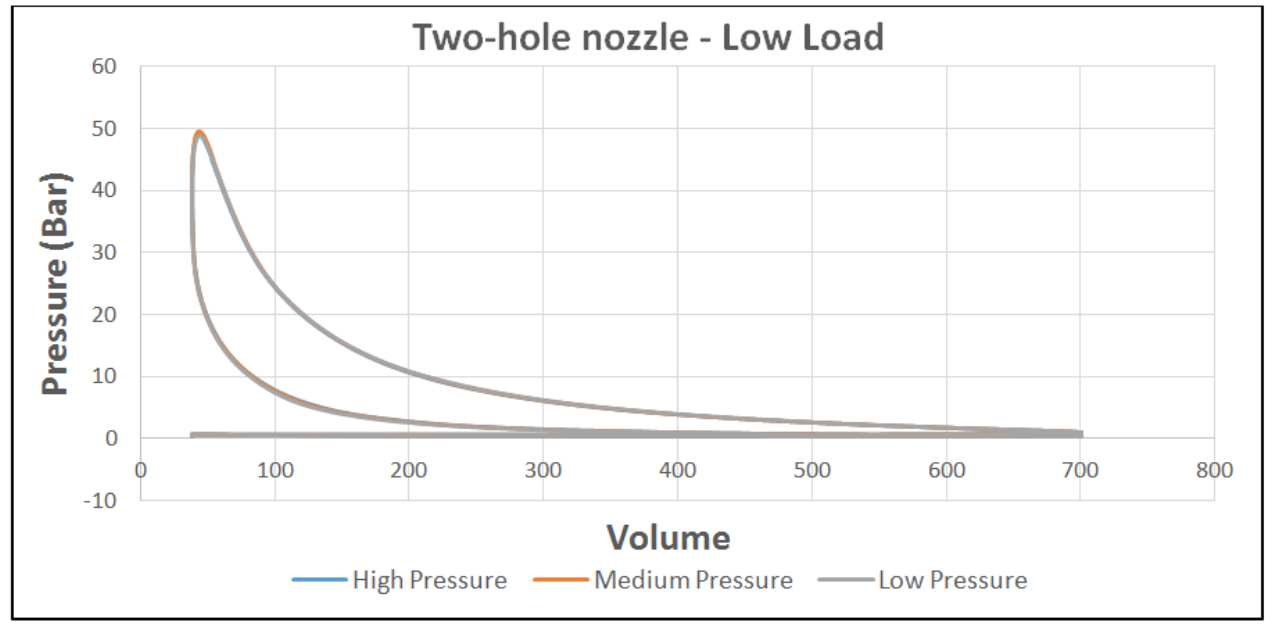

Fig.8: Pressure V/S Volume (P-V) graph for Low Load with two-hole nozzle

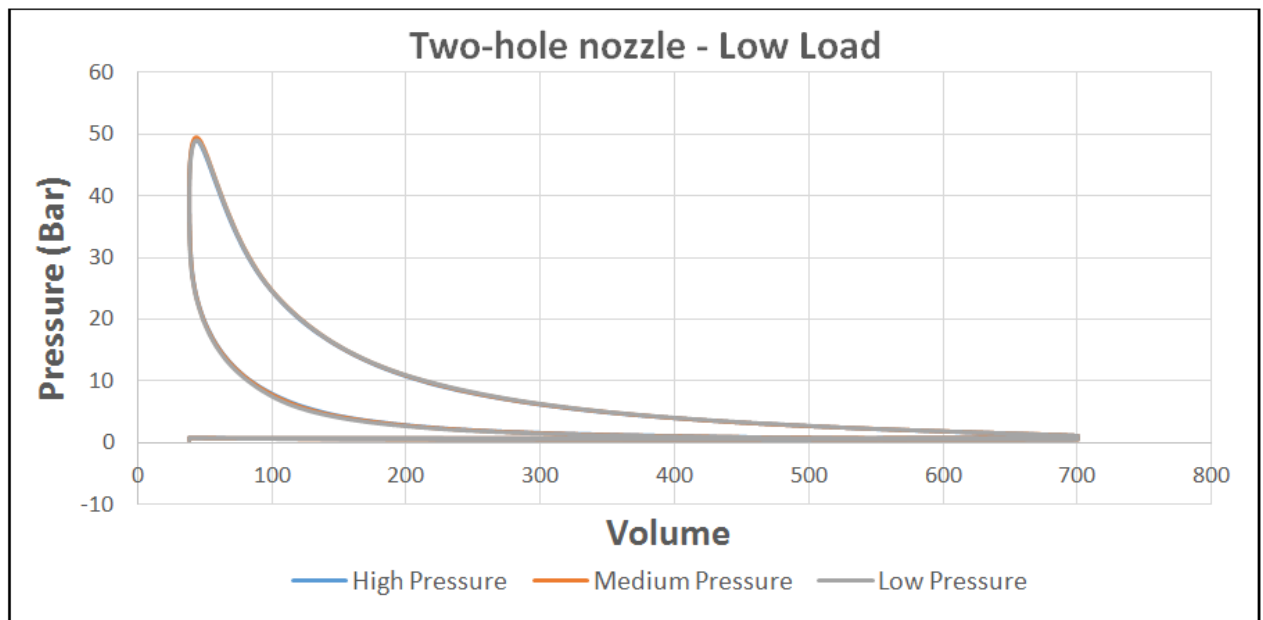

Fig.9: Pressure V/S Volume (P-V) graph for Low Load with single-hole nozzle 
Figure 8 and Figure 9 shows Pressure - Volume (P-V) graph the graph for low load including all the injection pressures. From graph we can conclude the changes in volume $\&$ pressure in the system by the combustion for all the injection pressure is same for two-hole nozzle and it varies at all injection pressure for single-hole nozzle.

The volume at various pressure created by the combustion is at peak level of 50 bar for all injection pressure in two-hole nozzle, and for single-hole nozzle also peak of 50 bar for low injection pressure and peak at 47 bar for high and medium injection pressure.

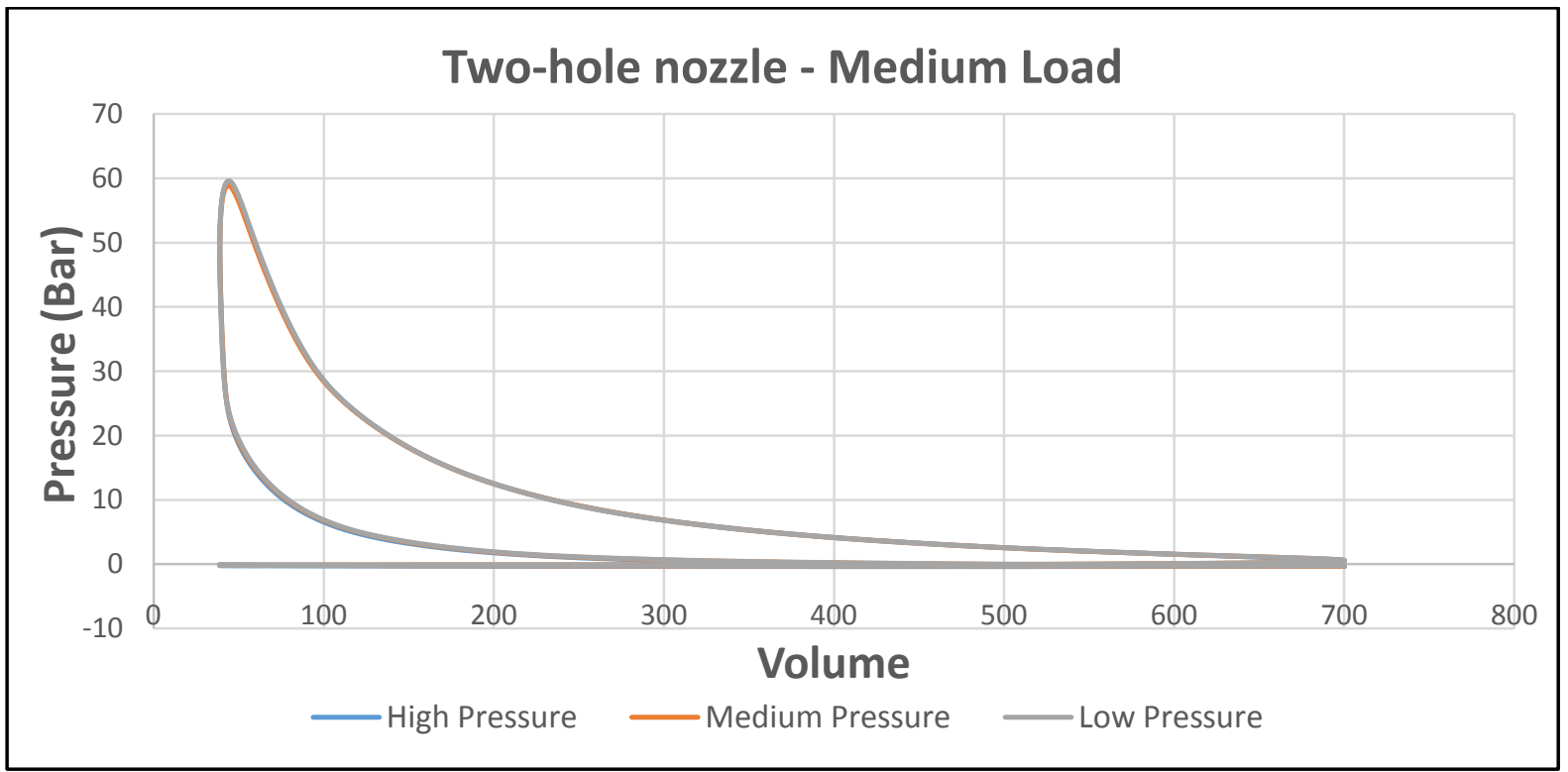

Fig.10: Pressure V/S Volume (P-V) graph for Medium Load with two-hole nozzle

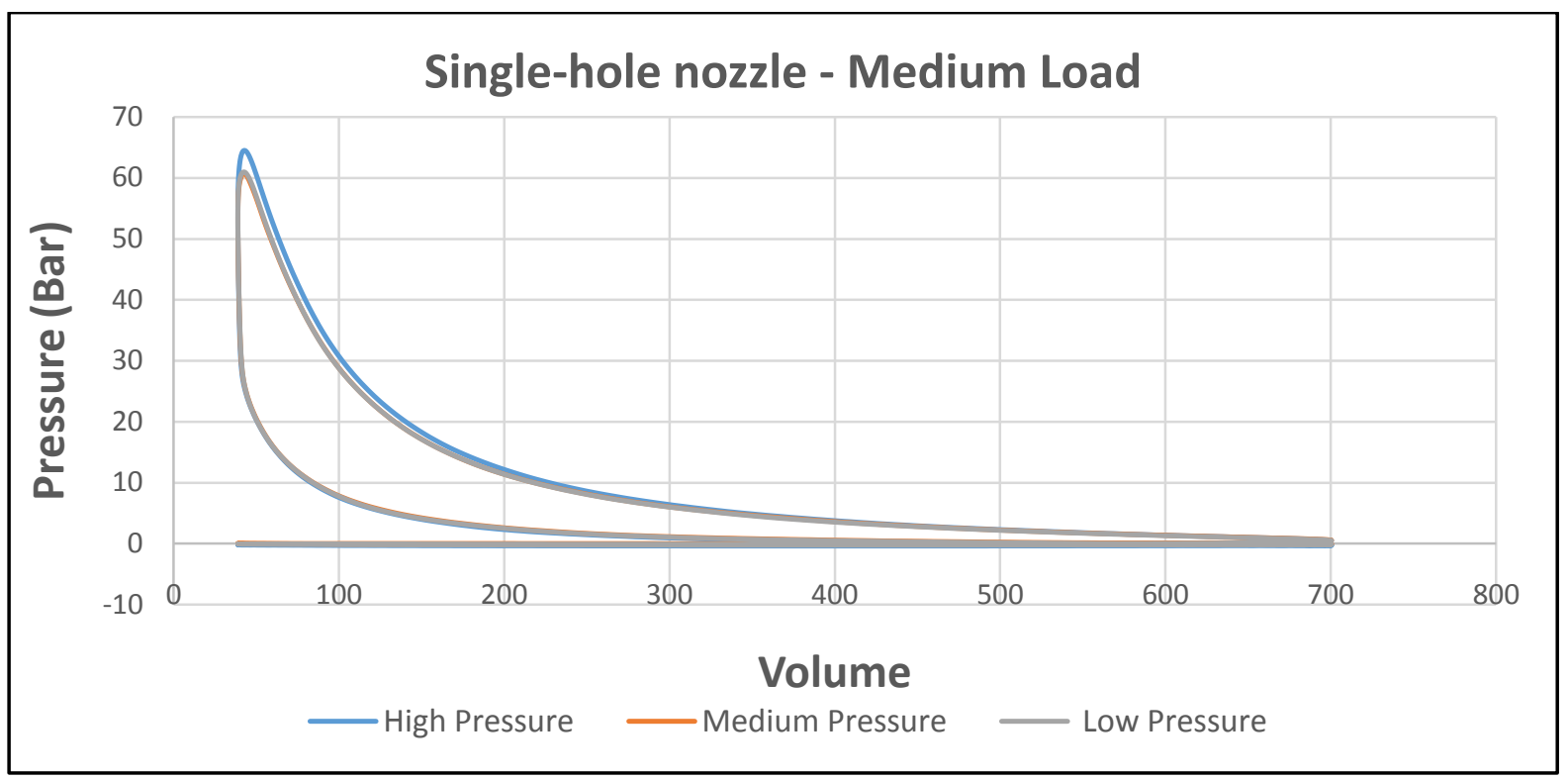

Fig.11: Pressure V/S Volume (P-V) graph for Medium Load with single-hole nozzle

Figure 10 and Figure 11 shows Pressure - Volume (P-V) graph the graph for medium load including all the injection pressures. From graph we can conclude the changes in volume \& pressure in the system by the combustion for all the injection pressure is same for two-hole nozzle and it varies for at various injection pressure for single-hole nozzle.

The volume at various pressure created by the combustion is at peak level of 60 bar for all pressure in two-hole nozzle, and for single-hole nozzle also peak of 65 bar for high injection pressure. 


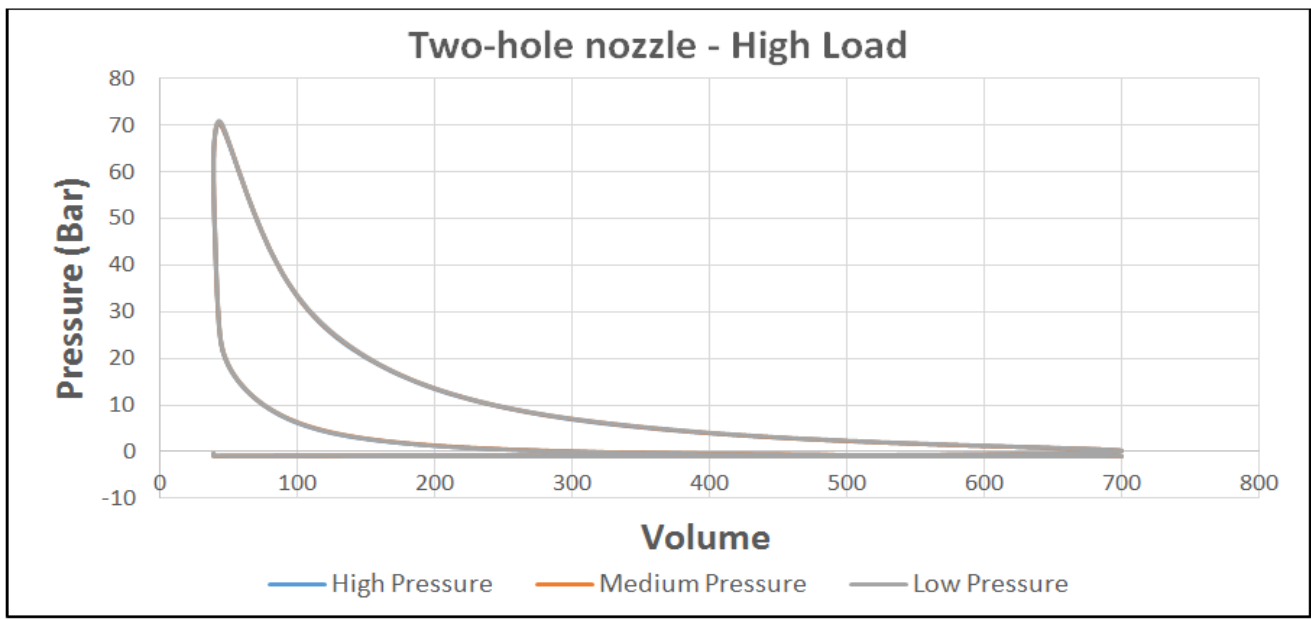

Fig.12: Pressure V/S Volume (P-V) graph for High Load with two-hole nozzle

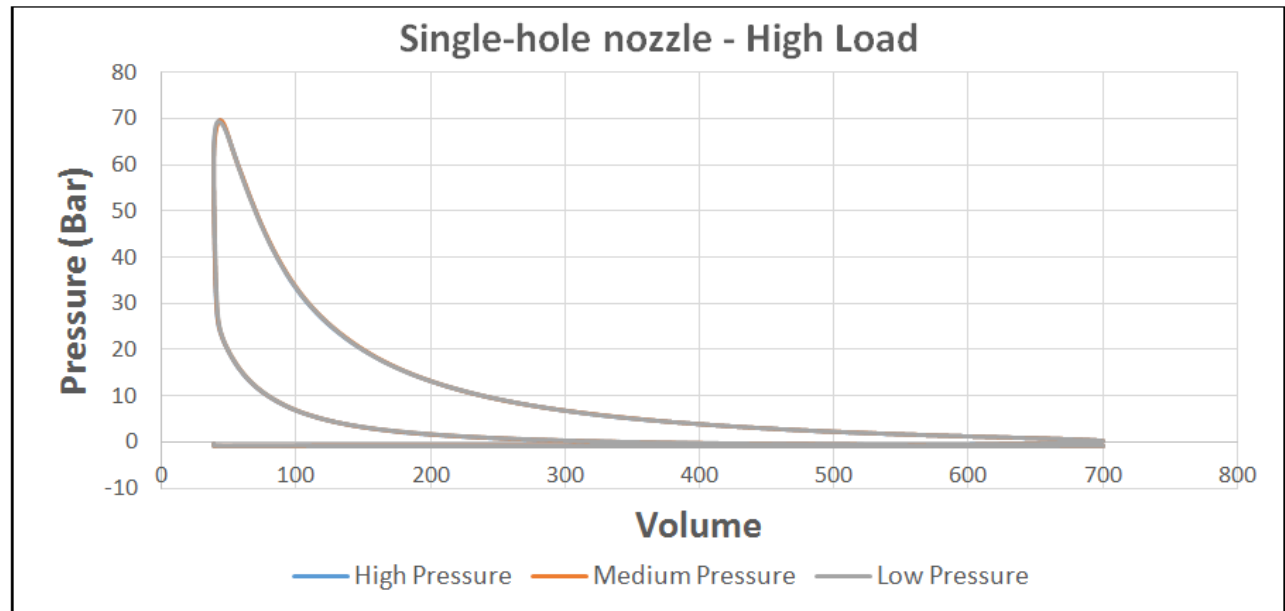

Fig.13: Pressure V/S Volume (P-V) graph for High Load with single-hole nozzle

Figure 12 and Figure 13 shows Pressure - Volume (P-V) graph the graph for high load including all the injection pressures. From graph we can conclude the changes in volume \& pressure in the system by the combustion for all the injection pressure is same for two-hole nozzle and same also for the all injection pressure for single-hole nozzle.

The volume at various pressure created by the combustion is at peak level of 70 bar for all pressure in two-hole nozzle, and for single-hole nozzle also peak of 68 bar for all injection pressure.

\section{Discussions of results for Fuel-Line Pressure}

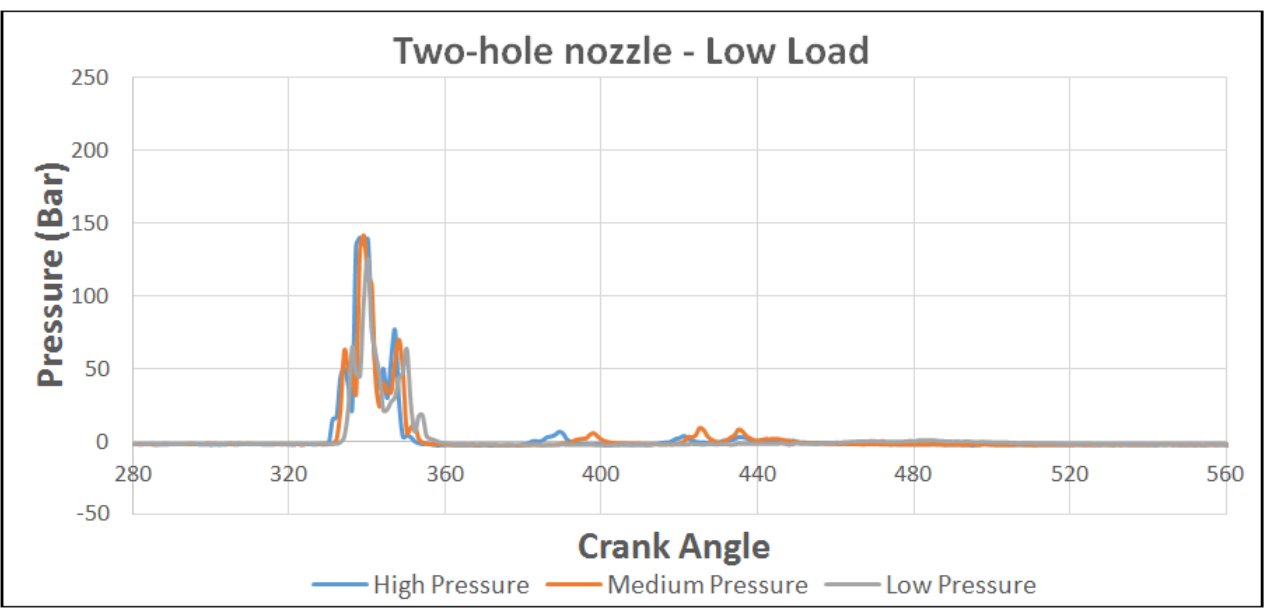

Fig.14: Fuel Line Pressure V/S Load graph for Low Load with two-hole nozzle 


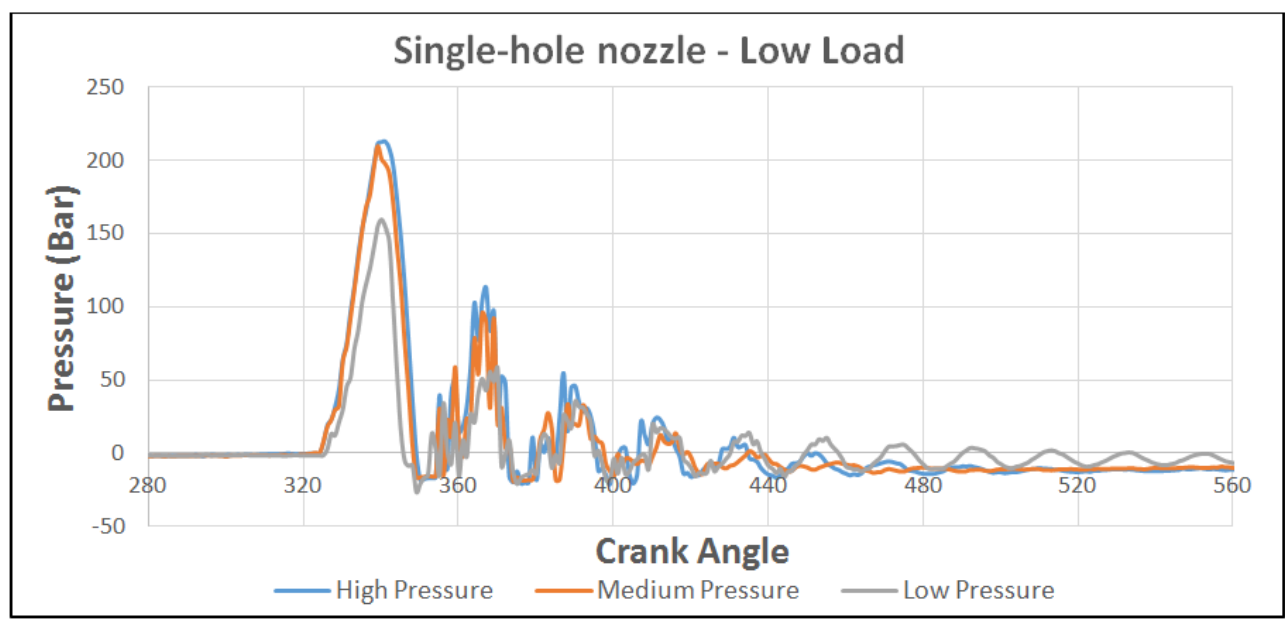

Fig.15: Fuel Line Pressure V/S Load graph for Low Load with single-hole nozzle

Figure 14 and Figure 15 shows Fuel line pressure V/S Load graph for low load including all the pressures. From graph we can conclude that in two hole nozzle the pressure of the fuel line is maximum about $140 \mathrm{bar}$ at time of injection and it comes to steady state uniformly after $20^{\circ}$ crank angle, while in single-hole nozzle the pressure of fuel line is maximum about 210 bar at the time of injection but the disturbance is created in single hole nozzle. The amplitude of disturbance within specific range of crank angle is less as compared to the others. The unsteadiness comes to normal condition quickly with the approach of crank angle.

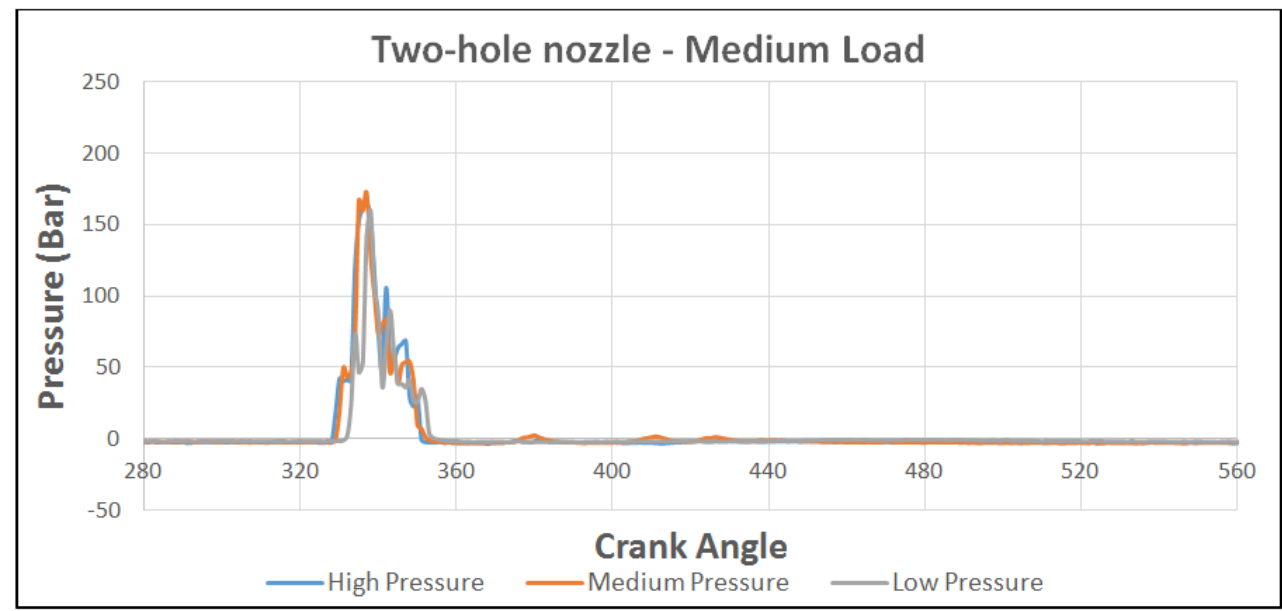

Fig.16: Fuel Line Pressure V/S Load graph for Medium Load with two-hole nozzle

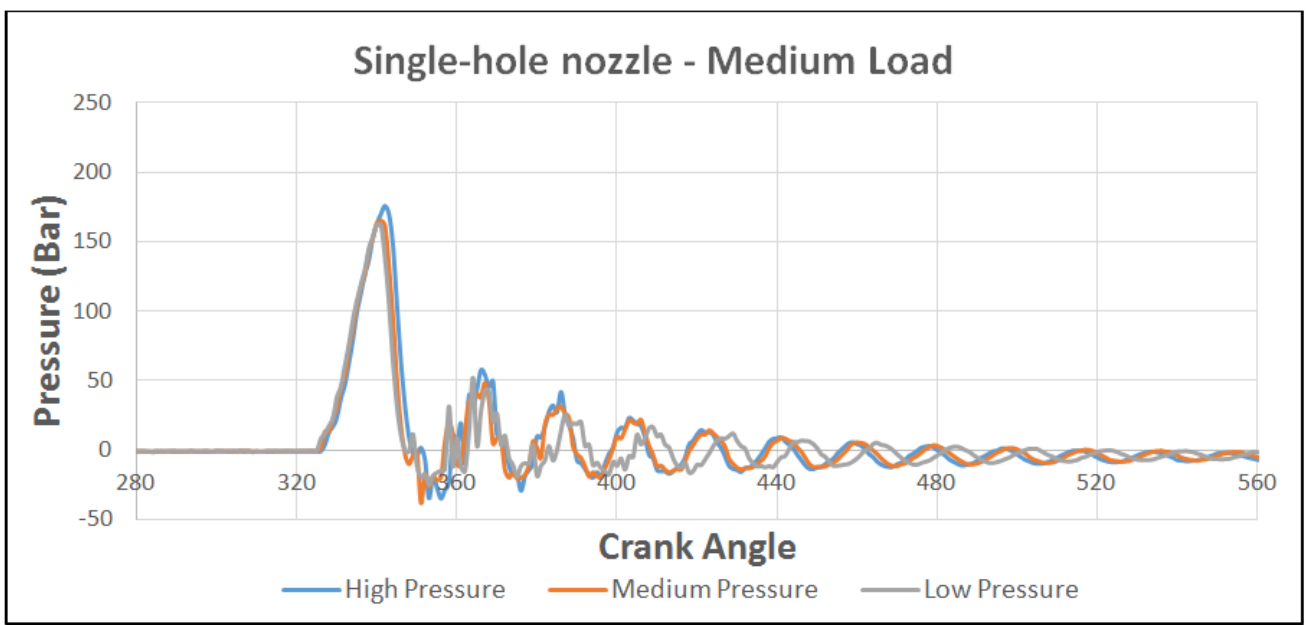

Fig.17: Fuel Line Pressure V/S Load graph for Medium Load with single-hole nozzle 
Figure 16 and Figure 17 shows Fuel line pressure V/S Load graph for low load including all the pressures. From graph we can conclude that in two hole nozzle the pressure of the fuel line is maximum about 155 bar at time of injection and it comes to steady state uniformly after $20^{\circ}$ crank angle, while in single-hole nozzle the pressure of fuel line is maximum about 162 bar at the time of injection but the disturbance is created in single hole nozzle. The amplitude of disturbance within specific range of crank angle is more as compared to low load condition. The unsteadiness comes to normal condition within little time with the approach of crank angle.

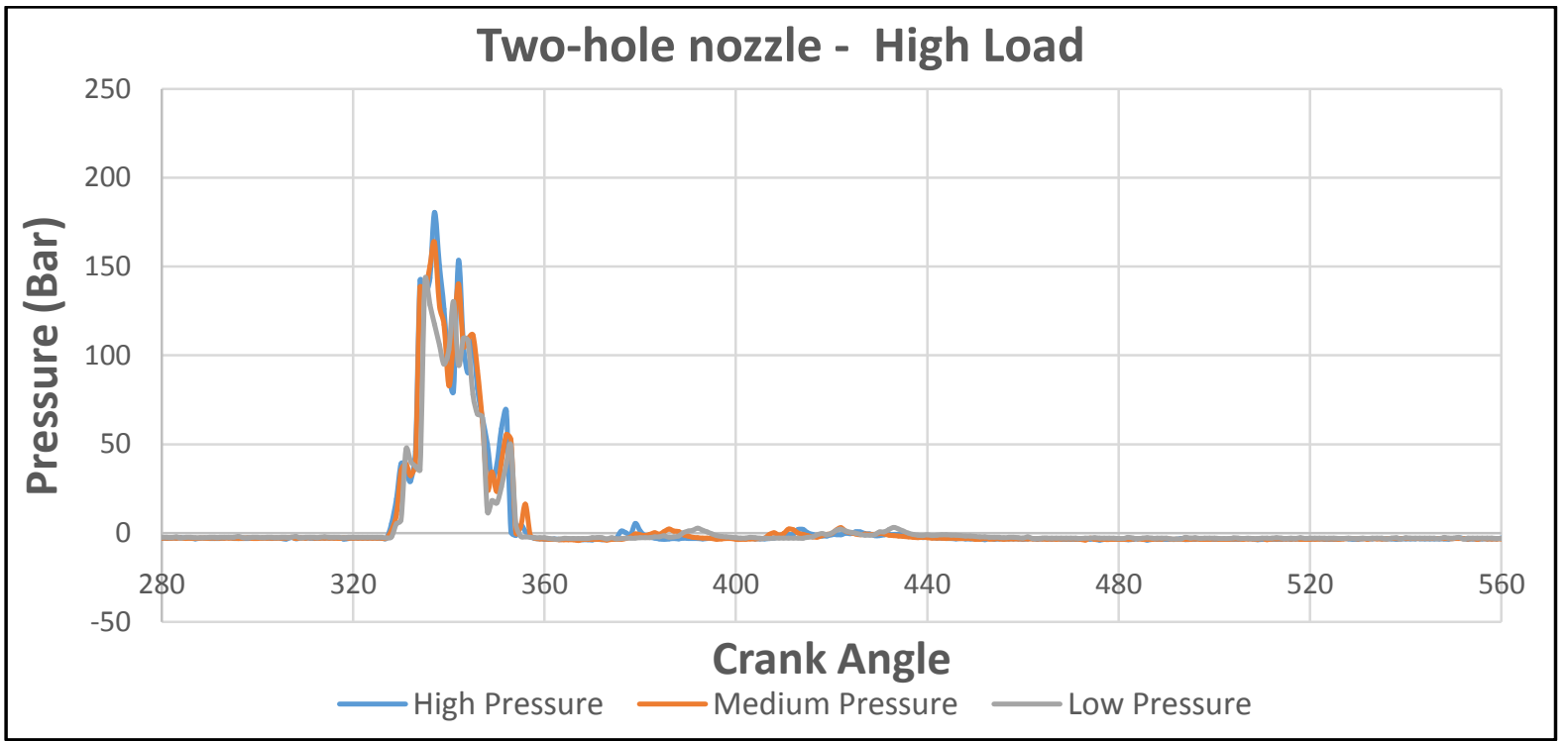

Fig.18: Fuel Line Pressure V/S Load graph for higher load with two-hole nozzle

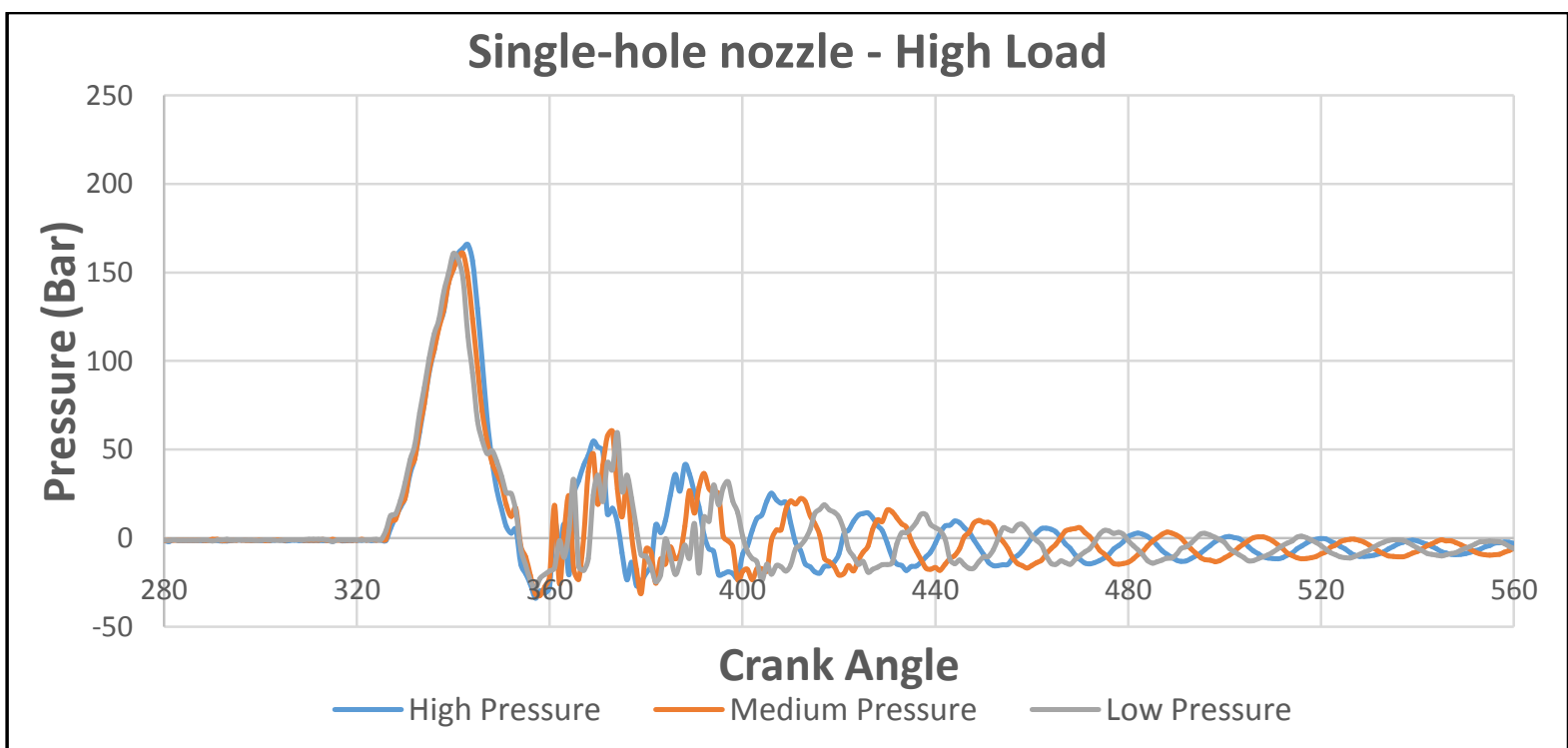

Fig.19: Fuel Line Pressure V/S Load graph for high load with Single-hole nozzle

Figure 18 and Figure 19 shows Fuel line pressure V/S Load graph for low load including all the pressures. From graph we can conclude that in two hole nozzle the pressure of the fuel line is maximum about $160 \mathrm{bar}$ at time of injection and it comes to steady state uniformly after $20^{\circ}$ crank angle, while in single-hole nozzle the pressure of fuel line is maximum about 165 bar at the time of injection but the disturbance is created in single hole nozzle. The amplitude of disturbance within specific range of crank angle is more as compared to low and medium load condition. The unsteadiness comes to normal condition within long time with the approach of crank angle. 


\section{Conclusion}

- The value of pressure at the time of combustion is increasing with the increase in load for both the nozzles.

- The pressure inside the cylinder at the time of combustion is same for all the injection pressure in case of two-hole nozzle, while in case of single-hole nozzle the pressure inside the cylinder vary for all the injection pressure.

- The volume of combustion taking place inside the engine cylinder is increasing with the increase in load.

- The volume of combustion taking place inside the engine cylinder is same at all the injection pressure for two-hole nozzle, while in case of single-hole nozzle the volume inside the engine cylinder vary for all the injection pressure.

- The fuel line pressure is very less for two-hole nozzle while for single-hole it is at extreme level and becomes stable over a large range of crank angle.

- The working of single-hole nozzle tries to work similar as two-hole nozzle as there is increase in load.

Journal Papers:

\section{References}

[1] R. Chen, \& N. Milovanovic (2002), A computational study into the effect of exhaust gas recycling on homogeneous charge compression ignition combustion in internal combustion engines fuelled with methane. International Journal of Thermal Sciences, 41(x), 805-813.

[2] H. Chen, S. Shuai \& J. Wang, (2007), Study on combustion characteristics and PM emission of diesel engines using ester - ethanol diesel blended fuels. Proceedings of the Combustion Institute 31, 2981-2989.

[3] N. Saravanan, G. Nagarajan, G. Sanjay, C. Dhanasekaran \& K. M. Kalaiselvan (2008), Combustion analysis on a DI diesel engine with hydrogen in dual fuel mode. Fuel, 87(17-18), 3591-3599.

[4] M. Canakci, A. N. Ozsezen, \& A. Turkcan, (2009). Combustion analysis of preheated crude sunflower oil in an IDI diesel engine. Biomass and Bioenergy, 33(5), 760-767.

[5] K. Muralidharan, \& D. Vasudevan, (2011). Performance, emission and combustion characteristics of a variable compression ratio engine using methyl esters of waste cooking oil and diesel blends. Applied Energy, 88(11), 3959-3968.

[6] P. V. Rao, (2011). Experimental Investigations on the Influence of Properties of Jatropha Biodiesel on Performance , Combustion , and Emission Characteristics of a DI-CI Engine, World academy of science, engineering and technology, Vol:5 2011-03-23.

[7] D. H. Joshi, \& T.M. Patel, (2012). Parametric optimization of single cylinder diesel engine for pyrolysis oil \& diesel blend for mechanical efficiency using taguchi method, International Journal of Engineering Research \& Technology 1(4), 1-6.

[8] K. Varatharajan \& M. Cheralathan, (2013). Effect of aromatic amine antioxidants on NOx emissions from a soybean biodiesel powered di diesel engine. Fuel Processing Technology, 106(x), 526-532.

[9] M.A. Modi, T.M. Patel \& G.P. Rathod (2014). PARAMETRIC OPTIMIZATION OF SINGLE CYLINDER DIESEL ENGINE BY TAGUCHI APPROACH USING PALM SEED BIODIESEL, ICCIET 1-5.

[10] A. K. Panchal, C. M. Patel, G. P. Rathod, \& T. M Patel, (2014). Performance and Exhaust Gas Emission of Compressed Natural Gas Fueled Internal Combustion Engine in Dual Fuel Mode Performance and Exhaust Gas Emission of Compressed Natural Gas Fueled Internal Combustion Engine in Dual Fuel Mode, International Journal for Research in Technological Studies 1(6) 96-104.

[11] R.H. Padhiyar, A.B. Patel, T.M. Patel \& G.P. Rathod (2014). Performance \& Emission Analysis of Urea Based Catalytic Convertor in CI Engine, International Journal for Scientific Research \& Development 2(3), 585-589.

[12] B.P. Patel, I.J. Patel, T.M. Patel, G.P. Rathod (2014). EFFECT OF SPIRAL GROOVES IN PISTON BOWL ON EXHAUST EMISSIONS OF DIRECT INJECTION DIESEL ENGINE, International Journal of Research in Engineering and Technology (1), $131-135$.

[13] M. D. Trivedi, P.R Patel, T.M. Patel, \& G.P. Rathod (2014). Review on Performance and Emission of C.I Engine Fuel Blended With Sesame Oil and Diesel, International Journal for Scientific Research \& Development 2(10), 602-604.

[14] A. Jani, T.M. Patel, \& G.P Rathod (2015). Effect of Varying Load on Performance and Emission of C.I. Engine Using WPO Diesel Blend. IOSR Journal of Mechanical and Civil Engineering Ver. V, 12(2), 2320-334.

[15] C.M. Patel, P.R. Patel, T.M. Patel, \& G.P. Rathod (2015). Parametric Optimization of NO x Emissions using Taguchi Method for C.I Engine Fuel with Plastic Pyrolysis Oil, International Journal for Scientific Research \& Development 3(1), $1373-1376$.

[16] B. V. Chauhan, G. P. Rathod, \& T.M. Patel, (2016). An Experimental Investigation of HHO Gas and Varying Compression Ratio on Performance Characteristics of Constant Speed Diesel Engine, IOSR Journal of Mechanical and Civil Engineering (IOSR-JMCE) $13(2), 41-47$. 